\title{
Caffeinated Drinks and the Human Body
}

\author{
Abhinav Dixit ${ }^{1} \cdot$ Praveen Sharma $^{2}$
}

Published online: 21 March 2016

(C) Association of Clinical Biochemists of India 2016

The last decade has seen a growth in marketing and consumption of the so called "Energy Drinks" in India. These drinks are non-alcoholic and contain stimulants like caffeine along with taurine, glucuronolactone, vitamins etc. [1].

The widespread use of these drinks has occurred due to publicity as their being an instant source of energy. The young generation is consuming more of these as compared to healthier substitutes like juices. These caffeinated drinks are being sold under different brands but there is no regulation on their ingredients, use and contraindications. At some places they are being promoted as health supplements.

The main ingredient of these drinks is caffeine which is chemically 1,3,7-trimethylxanthine. Caffeine is also present in other drinks consumed by humans like tea, coffee and colas and its amount vary from $24-50 \mathrm{mg} / 150 \mathrm{ml}$ of tea to $40-180 \mathrm{mg} / 150 \mathrm{ml}$ of coffee [2].

Caffeine is readily absorbed from oral, rectal and parenteral routes and has a half-life of 3-7 h in the human body. Significant levels of caffeine are detected in the brain within $5 \mathrm{~min}$ of oral intake with peak levels in about $30 \min [3]$.

Caffeine acts via various mechanisms in the human body. One of the mechanisms is mobilization of intracellular calcium. It has also been shown to act via inhibition of phosphodiesterase. Another mechanism of action is via binding to benzodiazepine receptors.

Praveen Sharma

praveensharma55@gmail.com

1 Department of Physiology, All India Institute of Medical Sciences, Jodhpur, India

2 Department of Biochemistry, All India Institute of Medical Sciences, Jodhpur, India
The main mechanism of action of caffeine is believed to be by blocking of adenosine receptors. The adenosine receptors have a widespread distribution in the human brain with maximum concentrations in hippocampus, cerebellar and cerebral cortex [4]. Caffeine by blocking adenosine receptors brings about changes in the levels of neurotransmitters like adrenaline, dopamine, serotonin, acetylcholine, glutamate and GABA.

The growth in the consumption of caffeinated drinks has been sparked by the publicity of the beneficial effects of caffeine. Caffeine increases the alertness levels and allays fatigue. Caffeine has been shown to improve information processing by the brain, sensory functions and the motor response [5-7].

However, there is also a flip side to the use of caffeine. Doses ranging from 400 to $800 \mathrm{mg}$ in one sitting, may lead to tachycardia, nervousness, aggressiveness, insomnia and anxiety. Energy drinks have been reported to increase the risk of stroke and heart diseases along with alteration in clotting of blood. Extended use over long periods of time can lead to caffeinism with dependence on caffeine along with unpleasant sensations during its withdrawal. According to DSM-IV criteria, four disorders have also been attributed to excessive caffeine use namely caffeine intoxication, caffeine-induced anxiety disorder, caffeine-induced sleep disorder, and caffeine-related disorder not otherwise specified. The Food Standards Agency in UK has advised against excessive consumption of caffeine by pregnant women.

There is an increase in consumption of "caffeinated" or "energy" drinks in the young especially in the age group of 18-24 years. These drinks are being marketed without a warning of the potential health hazards of consuming excess of caffeine [8].

The Food Safety and Standards Authority of India (FSSAI) has proposed regulations for these "Energy" or 
"Caffeinated" drinks [1]. The proposed regulations aim to identify the cut-off limit of caffeine in these drinks (currently proposed at $320 \mathrm{ppm}$ ) along with its justification.

The medical fraternity has an important role to play in the task of defining the safe limits as well the potentially harmful effects of consumption of excess of caffeine on the human body across different age groups.

\section{References}

1. Food Safety and Standards Authority of India Proposes Regulation of Energy Drinks, and Caffeine (Revised). www.fssai.gov.in/ portals/0/standards_of_energy_drinks_.pdf. Accessed on 1st Mar 2016.
2. Fredholm BB, Battig K, Holmen J, Nehlig A, Zvartau E. Actions of caffeine in the brain with special reference to factors that contribute to its widespread use. Pharmacol Rev. 1999;51(1):83-133.

3. Latini R, Bonati M, Castelli D, Garrattini S. Dose dependent kinetics of caffeine in rats. Toxicol Lett. 1978;2:267-70.

4. Fastbom J, Pazos A, Palacios JM. The distribution of adenosine A1 receptors and $5^{\prime}$-nucleotidase in the brain of some commonly used experimental animals. Neuroscience. 1987;22:813-26.

5. Smith A. Effects of caffeine on human behaviour. Food Chem Toxicol. 2002;40:1243-55.

6. Dixit A, Vaney N, Tandon OP. Evaluation of cognitive brain functions in caffeine users: a P3 evoked potential study. Indian J Physiol Pharmacol. 2006;50(2):175-80.

7. Dixit A, Vaney N, Tandon OP. Effect of caffeine on central auditory pathways: an evoked potential study. Hear Res. 2006;220(1-2):61-6.

8. Reissig CJ, Strain EC, Griffiths RR. Caffeinated energy drinks-a growing problem. Drug Alcohol Depend. 2009;99:1-10. 